\title{
Chronic inducible urticaria: classification and prominent features of physical and non-physical types
}

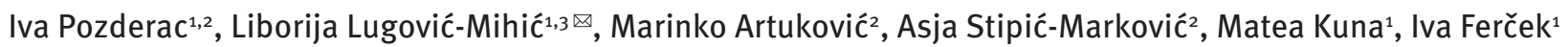

${ }^{1}$ Clinical Department of Dermatovenereology, Sestre milosrdnice University Hospital Center, Zagreb, Croatia. ${ }^{2}$ Clinical Department for Allergies, Clinical Immunology, and Pulmonology, Department of Internal Medicine, Special Hospital for Lung Diseases, Zagreb, Croatia. ${ }^{3}$ School of Dental Medicine, University of Zagreb, Zagreb, Croatia.

\begin{abstract}
Chronic inducible urticaria ( $\mathrm{ClndU}$ ) is a common inflammatory skin condition characterized by the recurrence of itchy wheals and/ or angioedema that lasts more than 6 weeks and is induced by specific physical or environmental stimuli (cold, heat, exercise, pressure, sunlight, vibration, water, etc.). According to the current international classification, it includes physical urticarias (dermographism, delayed-pressure urticaria, exercise-induced urticaria, cold urticaria, heat urticaria, solar urticaria, and vibratory urticaria) and non-physical urticarias caused by exposure to specific stimuli (cholinergic urticaria, contact urticaria, and aquagenic urticaria). In terms of frequency, more common types of CIndU are dermographism, cholinergic urticaria, and delayed-pressure urticaria. In clinical practice, it is often difficult to define the exact type of CIndU; management thus begins with accurate identification of a possible trigger and its avoidance. The definite diagnosis for CIndU requires obtaining a detailed medical history of a patient with comprehensive information about predisposing factors, physical examination, and provocation testing (challenge tests). It is always necessary to recognize the prophylactic options for all the types and to have access to different therapies (primarily second-generation $\mathrm{H}_{1}$ antihistamines, but also $\mathrm{H}_{2}$ antihistamines, hydroxyzine, doxepin, oral glucocorticoids, omalizumab/antiIgE therapy, phototherapy, physical desensitization, immunomodulatory agents, etc.) individualized for each patient.
\end{abstract}

Keywords: chronic inducible urticaria, classification, physical urticaria, non-physical urticaria, diagnostic, therapy, urticaria, angioedema

Received: 13 May 2020 | Returned for modification: 8 June 2020 | Accepted: 5 August 2020

\section{Introduction}

According to current guidelines, chronic urticaria can be classified into spontaneous (or idiopathic) and inducible forms (Table 1). Whereas spontaneous (or idiopathic) chronic urticaria occurs with no known reason, chronic inducible urticaria (CIndU) is triggered by various physical or non-physical factors.

Table 1 | Classification of chronic inducible urticaria (CIndU).

\begin{tabular}{ll}
\hline Physical urticarias & Non-physical urticarias \\
\hline Dermographism & Cholinergic urticaria \\
Delayed-pressure urticaria & Contact urticaria \\
Exercise-induced urticaria & Aquagenic urticaria \\
Cold urticaria & \\
Heat urticaria & \\
Solar urticaria & \\
Vibratory urticaria & \\
\hline
\end{tabular}

CIndU is a common inflammatory skin condition characterized by the recurrence of itchy wheals and/or angioedema that lasts more than 6 weeks and is induced by specific physical or environmental stimuli (cold, heat, exercise, pressure, sunlight, vibration, water, etc.) (1-7). The more common types include dermographism, cholinergic urticaria, and delayed-pressure urticaria/angioedema, whereas rare disorders are urticaria/angioedema caused by heat, exercise, water, sunlight, or vibration.

According to the current international classification, there are two types of CIndU: physical urticarias and non-physical urticarias (Table 2) (4, 8-14). The physical urticaria group includes dermographism (the most common), delayed-pressure urticaria (the third most frequent type), exercise-induced urticaria, cold urticaria, heat urticaria, solar urticaria, and vibratory urticaria. The non-physical urticaria group comprises cholinergic urticaria (the second most frequent type), contact urticaria, and aquagenic urticaria (4, 8-14). Physical urticarias are generally more common and occur in 10 to $50 \%$ of chronic urticaria patients and in up to $5 \%$ of the general population (12). The most frequent types in the physical urticaria group are dermographism and delayed-pressure urticaria (12). According to study data, in comparison to chronic spontaneous urticaria, CIndU equally often affects men and women, but it is generally more common in the younger population; less frequently, it is associated with angioedema (1).

With respect to diagnostics, CIndU can often be diagnosed on the basis of patient history and physical examination, as well as provocation testing $(2,9,12)$. Management begins with accurate identification and avoidance of triggers. The initial treatment includes primarily non-sedating $\mathrm{H} 1$ antihistamines (e.g., desloratadine, fexofenadine, bilastine, levocetirizine, loratadine, cetirizine, etc.). Therefore many patients require doubling of the standard dose. In cases unresponsive to antihistamines, a stepwise approach is suggested: $\mathrm{H} 2$ antihistamines, first-generation $\mathrm{H} 1$ antihistamines, systemic corticosteroids (for a short time), and omalizumab (a humanized monoclonal anti-immunoglobulin E, approved for refractory chronic urticarias). In persistent refractory cases, other therapies may include phototherapy, physical desensitization, and immunomodulatory agents. 


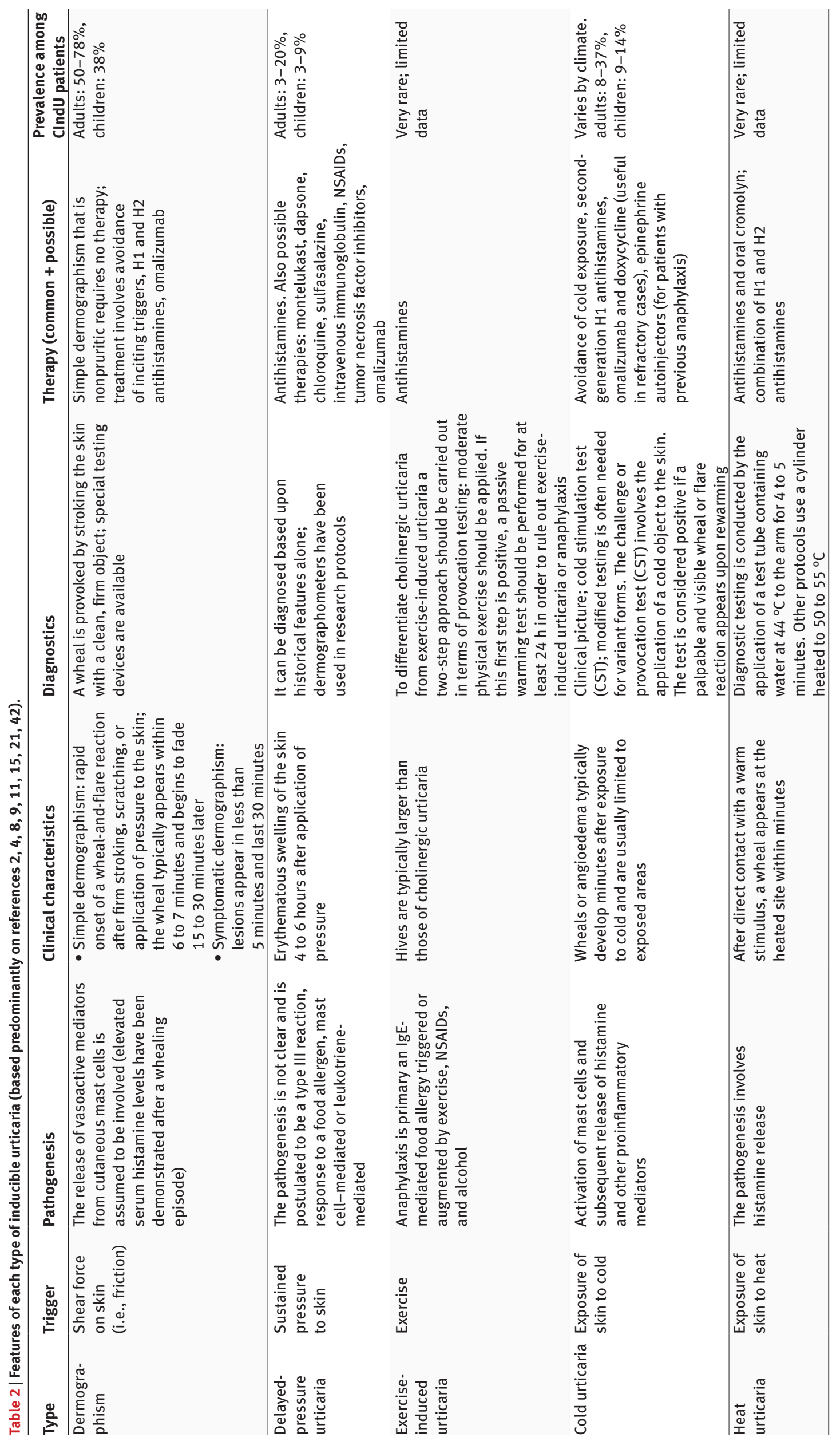




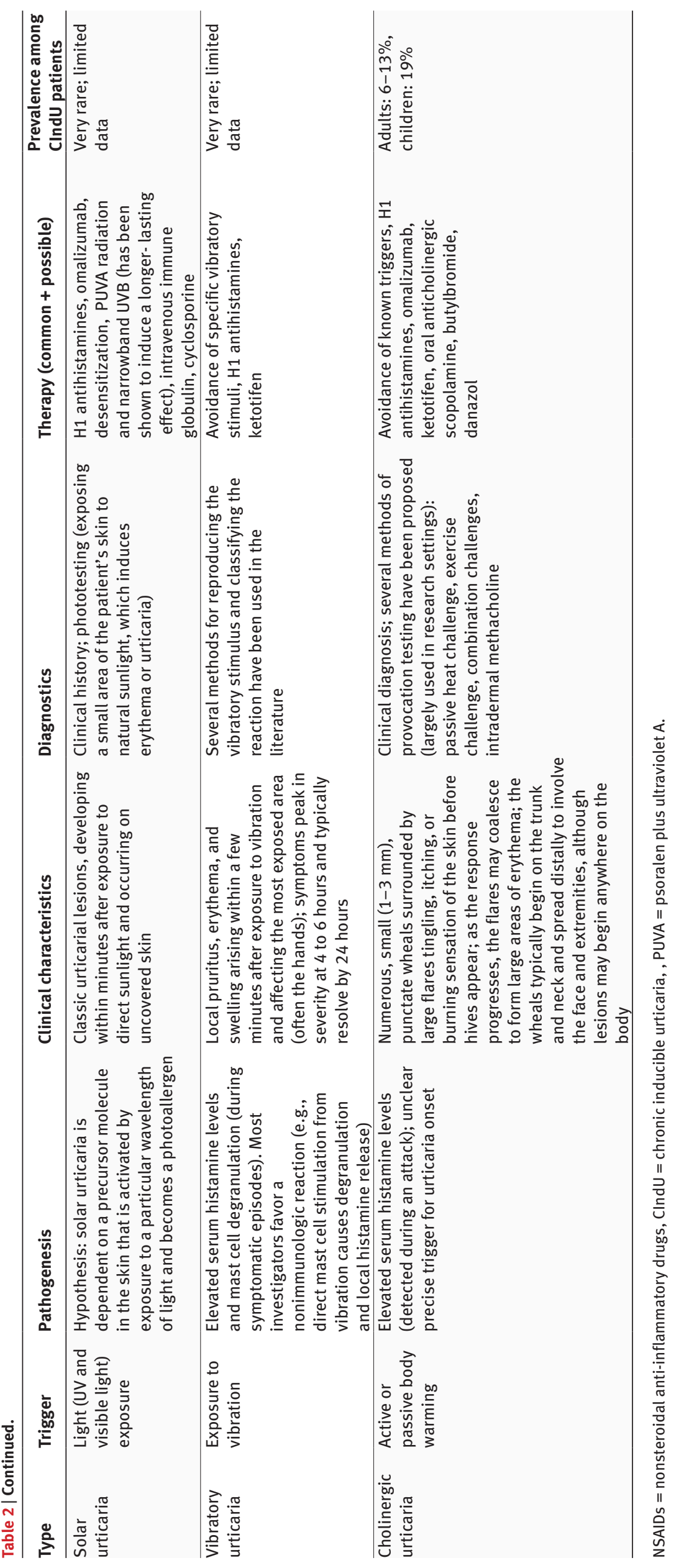




\section{Physical urticarias}

\section{Dermographism}

Dermographism (dermographic urticaria, urticaria factitia) is the most common type; it manifests as though someone has been writing on the skin, mostly occurring after firm stroking, scratching, or pressure on the skin (Fig. 1) $(2,15,16)$. The disease can manifest on various parts of the body. It is also found in patients with other skin conditions (atopic dermatitis, chronic spontaneous urticaria, and other inducible urticarias).

Generally, wheals quickly form or develop and persist for about 15 to 30 minutes. Two types are the most common: simple and symptomatic dermographism (2). Simple dermographism is the more common of the two; it does not include itching and it occurs in approximately 2 to $5 \%$ of the general population. The wheals typically appear within 6 to 7 minutes and begin to fade 15 to 30 minutes later. On the other hand, symptomatic dermographism is less common (usually occurring sporadically) and manifests with itchy hives that appear in less than 5 minutes and usually last 30 minutes (wheals are associated with an itch that becomes worse at night and with friction stimulated by a trigger: external stimuli, heat, stress, emotion, and exercise) (15). Sometimes the disease manifests as red dermographism characterized by follicular reactions or inflamed and swollen lesions predominantly on the trunk, scalp, and genital area (15). Apart from red dermatographism, there are some other rare types of dermatographism: follicular, cholinergic, delayed, cold-precipitated / exercise-induced, and familial (15). Follicular dermatographism includes isolated urticarial papules. The cholinergic type manifests similarly to cholinergic urticaria, with a large erythematous line marked by punctate wheals; the delayed type includes mild wheals reappearing 3 to 8 hours after the initial trigger and persisting up to 48

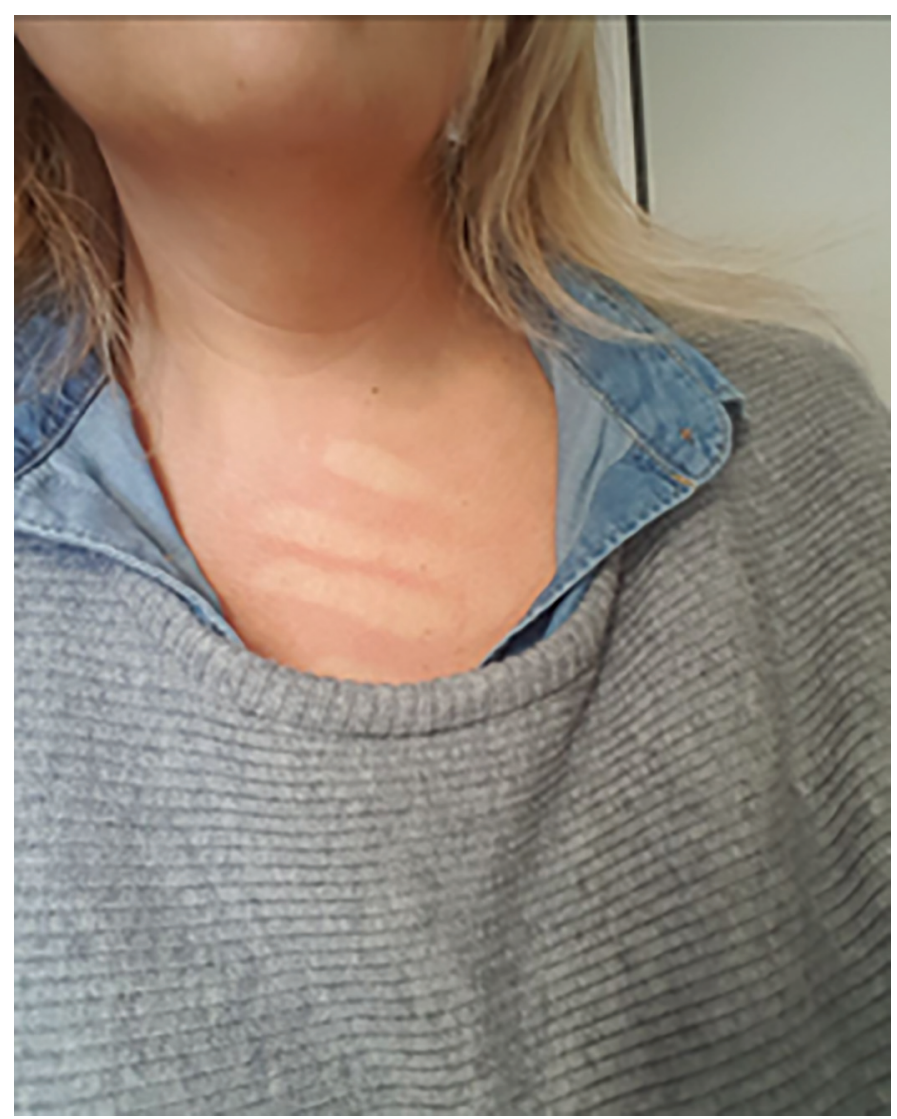

Figure 1 | Symptomatic dermographism. hours; the cold-precipitated / exercise-induced and familial types are uncommon.

The etiopathogenesis of dermographic urticaria is unknown. It is considered that the release of vasoactive mediators from the cutaneous mast cells is involved, as confirmed by elevated serum histamine. It is believed that skin inflammation may precede the onset of infections (bacteria, fungi, or viruses) or the effect of medications (e.g., penicillin).

Special testing devices are available for diagnostics; for example, challenge tests can be performed $(8,16)$. As far as therapy is concerned, simple dermographism requires no therapy, only avoidance of triggers (emollients are helpful sometimes), whereas therapies for symptomatic dermatographism include $\mathrm{H} 1$ antihistamines as the first-line therapy, primarily those of the secondgeneration with possible higher doses alone or in combination with other drugs such as $\mathrm{H} 2$ antihistamines. Sometimes first-generation $\mathrm{H} 1$ antihistamines are also useful. Other useful therapy options include omalizumab and cyclosporine, as well as phototherapy and photochemotherapy in some cases $(2,3,4,9,11)$.

\section{Delayed-pressure urticaria}

Delayed-pressure urticaria (or delayed-pressure angioedema) is a form of CIndU characterized by a recurrent erythematous and often painful swelling that appears after pressure to the skin (Fig. 2) $(2,17)$. Delayed-pressure urticaria is generally uncommon, but in frequency it ranks third among all inducible urticarias.

It typically occurs as an erythematous skin swelling that develops after 4 to 6 hours (range 0.5 to 12 hours) or sometimes immediately after a pressure stimulus; a prominent swelling can sometimes last several hours or even days (2). The peak age of the disease onset is in the 20 and 30s. The activities that typically induce the symptoms include wearing tight clothes (affecting constricted areas), sitting on a hard surface for prolonged periods, standing, extensive walking (affecting the soles and feet), carrying heavy bags (affecting the palms and hands), or compression against a pillow (affecting the face). Occasionally, delayed-pressure urticaria can be aggravated by heat, aspirin, or menstruation. The amount of pressure that induces symptoms can vary. The wheals consist of redness and cutaneous and subcutaneous swellings, which commonly occur on the hands, feet, trunk, buttocks, legs, and face (2). Patients often have an associated sense of burning and feel pain, but rarely itching or arthralgia. Lesions may last for 8 to 72 hours. Skin swelling can also be associated with fever, malaise, fatigue, and occasionally chills, headache, and general

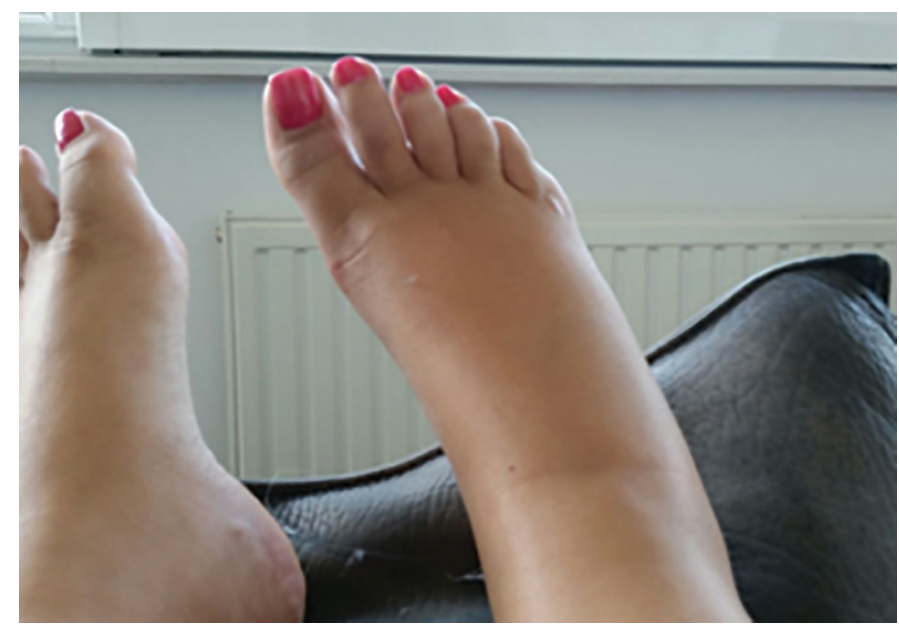

Figure 2 | Delayed-pressure urticaria. 
joint aches. In more than half of the patients (up to 60\%), there are other concomitant forms of chronic urticaria, immediate and/ or delayed dermographism, and/or angioedema $(2,17)$.

A diagnosis of delayed-pressure urticaria can be correctly based on patient history alone. Dermographometers may be used (especially in research protocols) $(2,8)$. A second approach is to hang a weight from the patient's arm for 20 minutes; for example, attaching a $5 \mathrm{~kg}$ weight to a sling. A $5 \mathrm{~kg}$ rod may also be placed across the patient's forearms for 20 minutes. The patient observes the skin for symptoms over the next 24 hours. The delayed appearance of an erythematous palpable swelling is considered a positive result.

The treatment of delayed-pressure urticaria is a continuing challenge. Although antihistamines are a first-line treatment; the disease usually does not respond to antihistamines alone, but rather to a combination of antihistamines (e.g., desloratadine) and leukotriene receptor antagonists. Other useful agents include a combination of antihistamines and montelukast, omalizumab, dapsone, sulfasalazine, anti-tumor necrosis factor (anti-TNF), or theophylline. Generally, antihistamines of the second generation remain a first-line therapy and their updosing is suggested for patients with uncontrolled disease $(2,4,9,11)$.

Delayed-pressure urticaria lasts a long time; the mean duration is 9 years. This is why patients often have problems and limitations in their everyday activities, especially those related to their jobs and physical labor.

\section{Exercise-induced urticaria}

Patients with cholinergic urticaria that develop hives after exercising or after any other trigger that elevates core body temperature may be at risk of anaphylaxis $(18,19)$. Exercise may trigger urticaria, which may also be an early manifestation of exercise-induced anaphylaxis. There are also other triggers, such as food. In exercise-induced anaphylaxis, exercise is the only trigger, and it may not be induced by passively raising the core body temperature.

There is a clinical similarity with cholinergic urticaria, but the hives in exercise-induced urticaria/anaphylaxis are typically larger in size than those in cholinergic urticaria (2). There are two types of disease: exercise-induced anaphylaxis and food-dependent, exercise-induced anaphylaxis. According to the literature, exercise-induced anaphylaxis is a primary IgE-mediated food allergy that is triggered or augmented by exercise, nonsteroidal anti-inflammatory drugs (NSAIDs), and alcohol. These increase intestinal permeability and allow increased antigen uptake, thus causing the disease symptoms. Consequently, hives and anaphylaxis occur shortly after patients exercise (19). Prompt treatment is necessary for patients.

\section{Cold urticaria}

Cold urticaria is characterized by pruritic hives/angioedema occurring after skin contact with cold objects, liquids, or air (20-27). It usually affects young atopic adults and is related to symptomatic dermographism and cholinergic urticaria, for example. The incidence of cold urticaria partly depends on geographic region (specifically, incidences are higher in regions with colder climates). The pathogenesis includes the activation of mast cells and their release of proinflammatory mediators. The disease may be associated with infections (viral, parasitic, or bacterial), Hymenoptera stings, food/drug intolerance, and hematologic, lym- phatic, or neoplastic conditions.

Clinically, wheals or angioedema typically develop minutes after exposure to cold and are usually limited to exposed areas, although extensive cold exposure (e.g., swimming in cold water) may trigger systemic reactions (e.g., anaphylaxis or respiratory, gastrointestinal, or cardiovascular reactions). The risk factors of systemic reactions are a previous cold-induced systemic reaction or oropharyngeal angioedema, age at onset $<30$ years, and greater and longer surface exposure at lower temperatures. There are several forms of cold urticaria, which all include hives with different triggers, timings, and localizations, but they all have negative standard cold stimulation tests (CST) (21). Therefore, delayed cold urticaria includes both acquired and hereditary forms, and clinically the wheal/flare reaction occurs up to 24 hours after cold exposure. Hereditary atypical cold urticaria begins in early childhood and is lifelong; localized hives typically develop on areas exposed to cold air, water, objects, food, and beverages, without systemic inflammatory symptoms. Cold-dependent dermographism only occurs when the skin is cold. Cold-induced cholinergic urticaria manifests with hives only when working out and exercising in cold environments. Systemic cold urticaria manifests after systemic cold exposure. Localized cold urticaria manifests with hives following cold exposure but only with specific localizations; for example, the face. Localized cold reflex urticaria hives develop near the site of the ice cube challenge.

The diagnostics of cold urticaria consist of a clinical picture (sometimes a CST), and modified testing is often needed for variant forms (21). Consequently, there is no need for laboratory testing in routine cases. The challenge/provocation test (CST) involves the application of a cold object to the skin; the test is considered positive if a palpable and visible wheal or flare reaction appears upon rewarming. The ice cube test involves placing an ice cube and a small amount of water in a thin plastic bag against the skin (volar forearm) for 5 minutes. The response is assessed 10 minutes after removal. Specialized testing devices have been developed, validated, and licensed for purchase. Threshold testing can sometimes be helpful. A diagnosis is confirmed by a positive CST. A variety of laboratory abnormalities are also found for cold urticaria, including mast cell-activating anti-IgEs, associated cryoglobulinemia, cold agglutinins, anti-lamin-B antibodies, and decreased values of $\mathrm{C}_{1}$ esterase inhibitor and $\mathrm{C}_{4}$ (21).

The treatment of cold urticaria includes the following: a) avoidance of cold exposure (complete avoidance is often difficult) and education about high-risk activities (e.g., swimming, surgery, or ingestion of cold foods or beverages); b) non-sedating $\mathrm{H} 1$ antihistamines are recommended for patients that are unable to avoid cold exposure and have frequent symptoms (the standard dose can be quadrupled); and c) omalizumab is useful in refractory cases, as well as cold desensitization and antibiotics (4, 9, 11, 21, 22, 27).

Generally, remission or improvement occurs in $50 \%$ of patients within 5 to 6 years, although it may take longer.

\section{Local heat urticaria}

Local heat urticaria is a rare disorder that appears after a warm stimulus comes into direct contact with the skin, resulting in hives and itchy erythema at the heated site within minutes $(28,29)$. The disease commonly appears in females between 20 and 45 years of age. The pathogenesis of local heat urticaria involves histamine release from mast cells (the immediate-type reaction), but there 
is also a hereditary variant of the disease that includes a delayed reaction type.

Clinically, local heat urticaria manifests as localized or generalized forms, depending on whether a skin area is directly exposed to heat (the localized form) or is a result of spreading to distant skin localizations (the generalized form) (29). Sometimes patients develop systemic symptoms such as weakness, wheezing, headache, nausea, vomiting, and tachycardia.

The diagnosis of local heat urticaria may be examined by challenge tests, which are also helpful in determining the critical temperature threshold (mean: about $44^{\circ} \mathrm{C}$ ). Therefore, diagnostic testing for local heat urticaria may be conducted by placing a test tube with hot water (at $44^{\circ} \mathrm{C}$ ) on the arm (for 4 to 5 minutes). Other protocols use a heated cylinder $\left(50-55^{\circ} \mathrm{C}\right)$. After removal of the heated object, localized hives develop within minutes. The mean threshold temperature is about $44^{\circ} \mathrm{C}$ (29).

Treatment options are limited. Because antihistamines and other agents (e.g., cromolyn) are often ineffective, other combinations may be tried (e.g., $\mathrm{H} 1$ antihistamines and $\mathrm{H} 2$ antihistamines). Also possible is a heat desensitization program and omalizumab treatment $(4,9,11,21,29)$.

Generally, local heat urticaria is a long-lasting disease with overall duration at the moment of diagnosis of approximately 2 years (29).

\section{Solar urticaria}

Solar urticaria is a rare disorder that involves the induction of hives, most commonly by direct exposure to sunlight (30-32). Based on retrospective studies, it affects only approximately $0.5 \%$ of chronic urticaria patients. There is a higher incidence of solar urticaria in women. Patient age at onset can vary, as can the atopic history and the wavelength of light responsible for the reaction. The possible pathogenesis of solar urticaria includes an unknown skin precursor molecule that is activated by exposure to a particular light wavelength and becomes a photoallergen (2). Therefore, IgEs are directed either against an abnormal photoallergen present only in affected patients (type I disease) or against a normal photoallergen present in most people (type II disease).

Clinically, there are classic hives that develop on uncovered skin within a few minutes after exposure to direct sunlight, although symptoms may also develop through thin clothes or glass $(2,30,31)$. Limited exposures provoke only itching or burning erythema. The severity of the symptoms increases with the intensity of sun exposure. Areas frequently exposed to sun are less sensitive than covered areas, but the exact mechanism (the "hardening" phenomenon) remains unknown.

The diagnosis of solar urticaria is based on patient history and sometimes on phototesting (2). A simple test may be performed by exposing a small area of the skin to natural sunlight. A more formal evaluation includes exposure to light sources that emit specific wavelengths of light (UVA and UVB, and visible light).

Regarding therapy, non-sedating $\mathrm{H} 1$ antihistamines (such as terfenadine in higher-than-standard doses) can reduce pruritus and hives but may not eliminate the erythema; topical and systemic corticosteroids are useful if antihistamines are insufficient. Other treatment approaches may be considered: desensitization, omalizumab, intravenous immunoglobulin treatment, and cyclosporine $(4.5 \mathrm{mg} / \mathrm{kg} /$ day) for refractory cases $(2,4,9,11)$.

The long-term outlook of solar urticaria is uncertain $(30,31)$. The patients themselves reported the following outcomes: com- plete resolution in $25 \%$ of cases, improvement in $32 \%$, unchanged condition in $35 \%$, and worsening in $8 \%$.

\section{Vibratory urticaria}

Vibratory urticaria, or vibratory angioedema, manifests with swelling after the application of a vibratory stimulus to the skin $(33,34)$. Clinically, there is local pruritus, erythema, and swelling without hives (within a few minutes after exposure) on the most exposed areas, often the hands. Common triggers include cutting grass, working with machinery, riding a motorcycle, horseback riding, or mountain biking. Thus, at-risk occupations include machinist, jackhammer operator, carpenter, and metal grinder operator. Regarding etiopathogenesis, hereditary forms have been found as consequences of mutation in the ADGRE2 gene (33). Thus the mutated receptor stimulates cell degranulation after exposure to vibration.

The symptoms of vibratory urticaria peak in severity in 4 to 6 hours and typically resolve in 24 hours, but sometimes they can persist for several days. The severity and duration of the manifestations generally match the size of the exposed surface (2).

In diagnosing vibratory urticaria, one method involves putting the arm on a vortex mixer for 10 minutes. The test is considered positive if the area becomes erythematous, pruritic, and edematous around the arm's full circumference. The treatment includes avoidance of specific vibratory stimuli (the first line of therapy), although this may not be possible in occupational cases. H1 antihistamines have been used successfully, and their dose could be increased. In case of a disease refractory to multiple antihistamines, possible therapy options include omalizumab (4, 9, 11, 34).

\section{Non-physical urticarias}

\section{Cholinergic urticaria}

Cholinergic urticaria manifests with characteristic hives triggered by active or passive heating of the body, exercise, strong emotions, or bathing in hot water (35-40). It accounts for approximately $30 \%$ of all inducible urticaria cases and approximately $5 \%$ of all spontaneous chronic urticarias. The onset of cholinergic urticaria typically occurs in a person's 20s or 30s, predominantly in young women. Patients experience approximately nine episodes per year.

Regarding the pathogenesis of the disease, there are many potential mechanisms involved in disease development (36). There are a few proposed theories of pathogenesis of cholinergic urticaria. The first theory is that the cholinergic nervous system causes cholinergic urticaria. In some patients, an intradermal injection of methacholine induces hives, which can be reversed with atropine. In lesions, an increase in the number of muscarinic receptors on mast cells was seen or recorded. Second, there is a possibility of an IgE-mediated allergy to some component of human sweat (some patients demonstrate immediate reactions to skin testing with their own diluted sweat). The third possible pathogenesis includes occlusion of the pores of the stratum corneum, which causes hypohidrosis and leakage of inflammatory sweat materials into the upper dermis, resulting in hives $(2,3)$.

Clinically, many patients with cholinergic urticaria first note tingling, itching, or burning sensations. Initially, numerous small (1-3 $\mathrm{mm}$ ) punctate wheals surround large flares typically beginning on the trunk or neck and spread to the face and extremities. 
The lesions may coalesce into large erythematous areas, or systemic symptoms may occur (e.g., hypotension, angioedema, and bronchospasm) (37).

A diagnosis of cholinergic urticaria is based on clinical presentation, but a few challenge methods are possible, primarily in research settings $(2,35,38)$. The passive heat challenge involves non-exertional elevation of the patient's core body temperature by placing one or both arms in a hot water bath $\left(40^{\circ} \mathrm{C}\right)$ until the core body temperature has increased by at least $0.7^{\circ} \mathrm{C}$. The appearance of generalized urticaria indicates cholinergic urticaria. The exercise challenge involves measurement of core or skin temperature while the subject performs exercise on a stationary bicycle or treadmill (30 minutes) to achieve a specified heart rate. Combination challenges are also possible. An intradermal injection of methacholine in saline $(0.01 \mathrm{mg} / 0.1 \mathrm{ml})$ that produces localized hives can be seen as confirmation.

In the therapy, identification and avoidance of the triggers are crucial. The most frequently used medications are non-sedating $\mathrm{H} 1$ antihistamines at twice the normal dosage. Other useful treatments include omalizumab, scopolamine butylbromide, methantheliniumbromide, combinations of propranolol, antihistamines, and montelukast, and desensitization (2, 4, 9, 11, 36, 40, 41).

The prognosis is generally good. According to one study, the average duration of symptoms is 7.5 years (ranging from 3 to 16 years).

\section{Contact urticaria}

Contact urticaria is the development of hives at a site of contact between an external agent and the skin or mucosa $(42,43)$. The symptoms range from pruritic localized wheal or flare reactions to generalized urticaria and anaphylaxis.

There are two types of this disease: non-immunologic contact urticaria and immunologic contact urticaria (42). Non-immunologic contact urticaria, the more common type, is an immediate reaction not requiring prior exposure to the substance. The symptoms usually occur only in the area of contact. Common causes are cosmetic ingredients, drugs, balsam of Peru, benzoic acid, cinnamic alcohol or aldehyde, and sorbic acid (a commonly used preservative in many foods, raw meat, fish, and vegetables). Immunologic contact urticaria is an IgE-mediated hypersensitivity reaction occurring in patients previously sensitized to a trigger. Previous sensitization can thus occur through contact with the skin or mucous membranes (respiratory or gastrointestinal). The reaction appears within minutes to hours, affecting the skin or sometimes other organs. Common causes include natural rubber latex (e.g., surgical gloves), antibiotics, metals, parabens, benzoic and salicylic acids, polyethylene glycol, short-chain alcohols, raw meat, fish, and vegetables $(42,44)$.

Clinically, the most commonly affected sites of contact urticaria are the hands, arms, and face. The eliciting factors typically arise in at-risk occupations: healthcare workers, food handlers, hairdressers, bakers, dental assistants, agricultural and diary workers, electronics workers, veterinary workers, and so on.

A diagnosis of contact urticaria is based on clinical presentation and patient history, which should include the time and duration of the onset, symptoms, distribution, family history, drug use, previous allergies or anaphylaxis, reaction to insect stings, and stress $(42,43,45)$. The diagnostics mostly include the open test, prick test, scratch test, and use test. The open test is first performed on unaffected skin. The prick test is performed next if the open test is negative. The scratch test is more useful for nonstandardized allergens.

In the treatment of contact urticaria, prevention is crucial. The first-line therapy includes non-sedating $\mathrm{H} 1$ antihistamines, which may be combined with $\mathrm{H} 2$ antihistamines $(4,9,11)$.

\section{Aquagenic urticaria}

Aquagenic urticaria is a very rare condition in which hives develop after direct skin contact with water (tap, distilled, or saline) (46-49). In some patients, salinity appears to be important; for example, reactions may occur only in contact with tap water or seawater, respectively. Women seem to have a slightly higher incidence than men, and the age at onset is during puberty. Familial occurrences have also been reported. Although the pathomechanism of this water-induced mast cell degranulation and histamine release is unclear, there are several theories of pathogenesis. One theory is that water solubilizes an antigen that permeates the skin and activates the dermal mast cells. Another is that interaction between water and sebum forms a substance that acts as a direct mast cell degranulator. The activation of the cholinergic pathway is essential in the pathogenesis of aquagenic urticaria.

Aquagenic urticaria is often similar to cholinergic urticaria because it manifests with characteristically small, punctate (1-3 $\mathrm{mm})$, perifollicular wheals. Thus, after contact with water, aquagenic urticaria typically appears quickly within 20 to 30 minutes on all body parts, predominantly on the upper limbs (except on the palms and soles). The wheals generally fade within 30 to 60 minutes. Systemic symptoms are rare but have been reported. It may be associated with other inducible urticarias; for example, dermographism, cholinergic urticaria, or cold urticaria. The disease usually occurs without symptoms, except with possible mild to severe itching and a burning sensation (49).

As far as the diagnosis for aquagenic urticarial is concerned, the standard diagnostic test is the application of a wet compress (at $35{ }^{\circ} \mathrm{C}$ ) to the upper body for 30 minutes, using ambient-temperature water to avoid confusion with cold-induced or local heat urticaria. The treatment primarily includes antihistamines. Other reported therapies include their combination with UV therapy (twice per week) $(2,4,9,11,47)$.

\section{Conclusions}

CIndU occurs due to exposure to specific stimuli and includes physical urticarias (dermographism, delayed-pressure urticaria, cold urticaria, heat urticaria, exercise-induced urticaria, solar urticaria, and vibratory urticaria) and non-physical urticarias (cholinergic urticaria, contact urticaria, and aquagenic urticaria). With respect to frequency, the common inducible urticarias include dermographism, cholinergic urticaria, and delayed-pressure urticaria or angioedema, whereas rarer types include urticaria or angioedema caused by heat, exercise, water, sunlight, or vibration. The diagnosis requires detailed medical history, physical examination, and provocation testing (physical challenge procedures) useful in identifying or confirming the triggering factor. In the treatment, second-generation $\mathrm{H} 1$ antihistamines are often used, but other useful treatments include $\mathrm{H} 2$ antihistamines, hydroxyzine, doxepin, oral glucocorticoids (for a short period of time), omalizumab (anti-IgE therapy), phototherapy, physical desensitization, and immunomodulatory agents (individualized for each patient). 


\section{References}

1. Curto-Barredo L, Pujol RM, Roura-Vives G, Gimenez-Arnau AM. Chronic urticaria phenotypes: clinical differences regarding triggers, activity, prognosis and therapeutic response. Eur J Dermatol. 2019;29:627-35.

2. Dice JP, Gonzalez-Reyes E. Physical (inducible) forms of urticaria. [Updated 2019 Dec 12]. Available from: www.uptodate.com/contents/physical-inducibleforms-of-urticaria.

3. Antia C, Baquerizo K, Korman A, Bernstein JA, Alikhan A. Urticaria: a comprehensive review: treatment of chronic urticaria, special populations, and disease outcomes. J Am Acad Dermatol. 2018;79:617-33.

4. Zuberbier T, Aberer W, Asero R, Abdul Latiff AH, Baker D, Ballmer-Weber B, et al. The EAACl/GA2LEN/EDF/WAO guideline for the definition, classification, diagnosis and management of urticaria. Allergy. 2018;73:1393-414.

5. Radonjic-Hoesli S, Hofmeier KS, Micaletto S, Schmid-Grendelmeier P, Bircher A, Simon D. Urticaria and angioedema: an update on classification and pathogenesis. Clin Rev Allergy Immunol. 2018;54:88-101.

6. Beck LA, Bernstein JA, Maurer M. A review of international recommendations for the diagnosis and management of chronic urticaria. Acta Derm Venereol. 2017; 97:149-58.

7. Lugović-Mihić L, Bukvić I, Bulat V, Japundžić I. Factors contributing to chronic urticaria/angioedema and nummular eczema resolution-which findings are crucial? Acta Clin Croat. 2019;58:595-603.

8. Maurer M, Fluhr JW, Khan DA. How to approach chronic inducible urticaria. J Allergy Clin Immunol Pract. 2018;6:1119-30.

9. Maurer M, Hawro T, Krause K, Magerl M, Metz M, Siebenhaar F, et al. Diagnosis and treatment of chronic inducible urticaria. Allergy. 2019;74:2550-3.

10. Dressler C, Werner RN, Eisert L, Zuberbier T, Nast A, Maurer M. Chronic inducible urticaria: a systematic review of treatment options. J Allergy Clin Immunol. 2018;141:1726-34.

11. Magerl M, Altrichter S, Borzova E, Giménez-Arnau A, Grattan CE, Lawlor F, et al. The definition, diagnostic testing, and management of chronic inducible urticarias-the EAACI/GA(2)LEN/EDF/UNEV consensus recommendations 2016 update and revision. Allergy. 2016;71:780-2.

12. Sánchez-Borges M, González-Aveledo L, Caballero-Fonseca F, Capriles-Hulett A. Review of physical urticarias and testing methods. Curr Allergy Asthma Rep. 2017;17:51.

13. Maurer M, Metz M, Brehler R, Hillen U, Jakob T, Mahler V, et al. Omalizumab treatment in patients with chronic inducible urticaria: a systematic review of published evidence. I Allergy Clin Immunol. 2018;141:638-49.

14. Abajian M, Schoepke N, Altrichter S, Zuberbier T, Maurer M. Physical urticarias and cholinergic urticaria. Immunol Allergy Clin North Am. 2014;34:73-88.

15. Nobles T, Schmieder GJ. Dermatographism. [Updated 2019 Dec 12]. In: StatPearls [Internet]. Treasure Island, FL: StatPearls Publishing; 2020 Jan-. Available from: https://www.ncbi.nlm.nih.gov/books/NBK531496/.

16. Mlynek A, Vieira dos Santos R, Ardelean E, Weller K, Magerl M, Church MK, et al. A novel, simple, validated and reproducible instrument for assessing provocation threshold levels in patients with symptomatic dermographism. Clin Exp Dermatol. 2013;38:360.

17. Rodríguez-Rodríguez M, Antolin-Amerigo D, Barbarroja-Escudero J, SánchezGonzález, MJ, Alvarez-Mon M. Successful treatment of severe delayed pressure angiooedema with omalizumab. Allergol Immunopathol (Madr). 2014;42:78-87.

18. Giannetti MP. Exercise-induced anaphylaxis: literature review and recent updates. Curr Allergy Asthma Rep. 2018;26:72.

19. da Silva DM, Vieira TM, Pereira AM, de Sousa Moreira AM, Delgado JL. Crossreactive LTP sensitization in food-dependent exercise-induced urticaria/anaphylaxis: a pilot study of a component-resolved and in vitro depletion approach. Clin Transl Allergy. 2016:22;6:46.

20. Deza G, Brasileiro A, Bertolín-Colilla M, Curto-Barredo L, Pujol RM, GiménezArnau AM. Acquired cold urticaria: clinical features, particular phenotypes, and disease course in a tertiary care center cohort. J Am Acad Dermatol. 2016;75: 918-24.

21. Maurer M. Cold urticaria. Available from: www.uptodate.com/contents/cold-urt icaria?topicRef $=8109$ \& source $=$ see_link.

22. Metz M, Schütz A, Weller K, Gorczyza M, Zimmer S, Staubach P, et al. Omalizumab is effective in cold urticaria-results of a randomized placebo-controlled trial. J Allergy Clin Immunol. 2017;140:864-7.

23. Gorczyza M, Curto-Barredo L, Krause K, Church MK, Hawro T, Metz M, et al. H1antihistamine inhibition of histamine- and codeine-induced wheals does not predict response in chronic cold urticaria. J Allergy Clin Immunol Pract. 2019;7: 2043-4.
24. Krause K, Spohr A, Zuberbier T, Church MK, Maurer M. Up-dosing with bilastine results in improved effectiveness in cold contact urticaria. Allergy. 2013;68:9218.

25. Kulthanan K, Hunnangkul S, Tuchinda P, Chularojanamontri L, Weerasubpong P, Subchookul C, et al. Treatments of cold urticaria: a systematic review. J Allergy Clin Immunol. 2019;143:1311-31.

26. Martinez-Escala ME, Curto-Barredo L, Carnero L, Pujol RM, Giménez-Arnau AM. Temperature thresholds in assessment of the clinical course of acquired cold contact urticaria: a prospective observational one-year study. Acta Derm Venereol. 2015;95:278-82.

27. Gorczyza M, Schoepke N, Krause K, Hawro T, Maurer M. Patients with chronic cold urticaria may benefit from doxycycline therapy. Br J Dermatol. 2017;176:259-61.

28. Darling M, Lambiase MC, Hodson DS. Localized heat induced urticaria: report of a case. J Drugs Dermatol. 2004;3:75-6.

29. Pezzolo E, Peroni A, Gisondi P, Girolomoni G. Heat urticaria: a revision of published cases with an update on classification and management. $\mathrm{Br} J$ Dermatol. 2016;175:473-8.

30. Beattie PE, Dawe RS, Ibbotson SH, Ferguson J. Characteristics and prognosis of idiopathic solar urticaria: a cohort of 87 cases. Arch Dermatol. 2003;139:114954 .

31. Du-Thanh A, Debu A, Lalheve P, Guillot B, Dereure O, Peyron JL. Solar urticaria: a time-extended retrospective series of 61 patients and review of literature. Eur J Dermatol. 2013;23:202-7.

32. de Dios-Velázquez Á, González-de Arriba M, Beteta-Gorriti V, Macías E, Campanón-Toro V, Dávila I. Effectiveness of omalizumab in severe solar urticaria. Ann Allergy Asthma Immunol. 2016;116:260-2.

33. Boyden SE, Desai A, Cruse G, Young ML, Bolan HC, Scott LM. Vibratory urticaria associated with a missense variant in ADGRE2. N Engl J Med. 2016;374:656-63.

34. Pressler A, Grosber M, Halle M, Ring J, Brockow K. Failure of omalizumab and successful control with ketotifen in a patient with vibratory angio-oedema. Clin Exp Dermatol. 2013;38:151-3.

35. Magerl M, Borzova E, Giménez-Arnau A, Grattan CE, Lawlor F, Mathelier-Fusade $P$, et al. The definition and diagnostic testing of physical and cholinergic urticarias-EAACl/GA2LEN/EDF/UNEV consensus panel recommendations. Allergy. 2009;64:1715-21.

36. Fukunaga A, Washio K, Hatakeyama M, Oda Y, Ogura K, Horikawa T, et al. Cholinergic urticaria: epidemiology, physiopathology, new categorization, and management. Clin Auton Res. 2018;28:103-13.

37. Vadas P, Sinilaite A, Chaim M. Cholinergic urticaria with anaphylaxis: an underrecognized clinical entity. J Allergy Clin Immunol Pract. 2016;4:284-91.

38. Altrichter S, Salow J, Ardelean E, Church MK, Werner A, Maurer M. Development of a standardized pulse-controlled ergometry test for diagnosing and investigating cholinergic urticaria. J Dermatol Sci. 2014;75:88-93.

39. Takahagi S, Tanaka T, Ishii K, Suzuki H, Kameyoshi Y, Shindo H, et al. Sweat antigen induces histamine release from basophils of patients with cholinergic urticaria associated with atopic diathesis. Br J Dermatol. 2009;160:426-8.

40. La Shell MS, England RW. Severe refractory cholinergic urticaria treated with danazol. J Drugs Dermatol. 2006;5:664-7.

41. Košnik M, Kopač P, Eržen R, Bajrović N, Adamič K, Lalek N, et al. Omalizumab in chronic urticaria: our experience and literature review. Acta Dermatovenerol Alp Pannonica Adriat. 2014;23:57-61.

42. Bhatia R, Alikhan A, Maibach HI. Contact urticaria: present scenario. Indian J Dermatol. 2009;54:264-8.

43. Mowad, CM. Contact Dermatitis: Practice gaps and challenges. Dermatol Clin. 2016;34:263-7.

44. Japundžić I, Vodanović M, Lugović-Mihić L. An analysis of skin prick tests to latex and patch tests to rubber additives and other causative factors among dental professionals and students with contact dermatoses. Int Arch Allergy Immunol. 2018;5:238-44.

45. Pondeljak N, Lugović-Mihić L. Stress-induced interaction of skin immune cells, hormones, and neurotransmitters. Clin Ther. 2020;42:757-70.

46. Kai AC, Flohr C. Aquagenic urticaria in twins. World Allergy Organ J. 2013;6:2.

47. Park H, Kim HS, Yoo DS, Kim JW, Kim CW, Kim SS, et al. Aquagenic urticaria: a report of two cases. Ann Dermatol. 2011;23:S371-4.

48. McGee JS, Kirkorian AY, Pappert AS, Milgraum SS. An adolescent boy with urticaria to water: review of current treatments for aquagenic urticaria. Pediatr Dermatol. 2014;31:116-7.

49. Wassef C, Laureano A, Schwartz RA. Aquagenic urticaria: a perplexing physical phenomenon. Acta Dermatovenerol Croat. 2017;25:234-7. 